\title{
Myocarditis in a 72-year-old woman with late onset systemic lupus erythematous
}

\author{
Miocarditis en una mujer de 72 años con lupus \\ eritematoso sistémico de inicio tardio
}

\author{
V. M. Santos ${ }^{1 *}$, L. R. Cruz $^{2}$, A. C. R. Holanda ${ }^{3}$, N. P. Machado ${ }^{4}$
}

\begin{abstract}
A 72-year-old female with late onset systemic lupus erythematosus (SLE) was admitted with chest pain and dyspnoea, and was submitted to investigation by echocardiogram, cardiovascular magnetic resonance (CMR) and serology panel. Morphological and functional studies of the heart revealed conspicuous inflammatory signs and moderate effusion compatible with myocarditis and pericarditis. Myocarditis is an uncommon manifestation of SLE. The additional burden posed by myocarditis in the management and outcome of elderly patients with SLE is also emphasized.
\end{abstract}

Key words. Late onset. Systemic lupus erythematosus. Myocarditis. Cardiovascular magnetic resonance.

\section{RESUMEN}

Se presenta el caso de una mujer de 72 años con lupus eritematoso sistémico (LES) de inicio tardío, que presentaba dolor torácico y disnea. Se realizó ecocardiograma y resonancia magnética cardíaca (CMR), y tests serológicos. Los estudios morfológicos y funcionales del corazón revelaron evidentes señales inflamatorios y moderada efusión pericárdica compatibles con miocarditis y pericarditis. La miocarditis es una manifestación poco común en el LES. Se enfatiza el problema adicional representado por la miocarditis en el manejo y el pronóstico de pacientes con LES.

Palabras clave. Inicio tardío. Lupus eritematoso sistémico. Miocarditis. Resonancia magnética cardiovascular.
1. Catholic University (UCB) and Internal Medicine Department from Armed Forces Hospital (HFA), Brasília-DF, Brazil

2. Internal Medicine Department from HFA

3. Rheumatology Division from HFA

4. Medical Course from (UCB)

Recepción: 23 de julio de 2011

Aceptación provisional: 5 de octubre de 2011

Aceptación definitiva: 7 de noviembre de 2011

\section{Corresponding author:}

Vitorino Modesto dos Santos, Armed Forces Hospital.

Estrada do Contorno do Bosque s/n, Cruzeiro Novo, 70658-900,

Brasília-DF, Brazil.

E-mail: vitorinomodestos@gmail.com

Financial disclosure: There was no grant support for this study.

Disclosure of potential conflicts of interest: The authors had full freedom of manuscript preparation and there were no potential conflicts of interest. 


\section{INTRODUCTION}

Late onset systemic lupus erythematosus (SLE) is characterized if disease onset occurs after the age of $50^{1-5}$. Insidious presentation, non-specific first clinical manifestations and low prevalence in elderly group contributes to misdiagnosis and diagnosis delay $^{5}$. Based on the indolent course, there was an old conception that late onset SLE was a benign entity, but recent data points to shorter survival and more accumulated organ damage ${ }^{1-5}$. Heart structural damage can be seen on magnetic resonance imaging, and confirmed by biopsy ${ }^{6-9}$. Cardiovascular disease plays a main role in outcomes of elderly people with SLE ${ }^{10,11}$. Clinical diagnosis of myocarditis is reported in less than $10 \%$ of patients with late onset SLE ${ }^{2,4,6,10}$ but autopsy studies found myocaditis in up to $40 \%$ of patients with lupus ${ }^{12}$. The aim of the present report is highlight the need of higher awareness about the hypothesis of myocarditis, a probably under detected condition which has been scarcely described in late onset SLE.

\section{CASE REPORT}

A 72 year-old white woman, with SLE diagnosed 12 years before, presented with acute chest pain, breathlessness, nausea, vomiting and headache for ten days. Before actual admission, she had been followed by rheumatologist on outpatient basis. Main clinical features were joint pains, mild arthritis, moderate pleuropulmonary involvement, and slow developing renal dysfunction. Evolution of disease was characterized by uneventful clinical course during more than a decade, with episodic manifestations invariably controlled with prednisone ( $2.5 \mathrm{mg}$ daily). She denied tobacco smoking, alcohol consumption, and use of non-steroid anti-inflammatory drugs, hydroxychloroquine or cyclophosphamide. Shortly before her hospitalization, she underwent a coronary arteriography that excluded any remarkable change. On admission, body mass index was normal; she was pale, with high blood pressure, dyspnoea, decreased pulmonary sounds and crackles bilaterally, and a systolic murmur in aortic and mitral focuses. Laboratory data are showed in table 1 . She had severe anaemia, haematuria (190.6 red cells/ $\mu \mathrm{l})$, high level of proteinuria (1.2 g/day), low creatinine clearance $\left(39 \mathrm{ml} / \mathrm{min} / 1.73 \mathrm{~m}^{2}\right)$, high D-dimmers $(3,185 \mathrm{mg} /$ $\mathrm{ml})$, elevated NT pro-BNP $(24,798 \mathrm{pg} / \mathrm{ml})$ and CKMB (3.67 ng/ml) levels, and low C3 (85 mg/dl) and C4 (1.54 mg/dl) complement. Serum levels of myoglobin and troponin were normal, and lipidogram showed high total cholesterol (174 mg/ dl) and normal triglycerides (119 mg/dl), HDL (49 $\mathrm{mg} / \mathrm{dl})$, LDL (101 mg/dl), and VLDL (23.8 mg/dl). Chest X-ray (Fig 1) showed congestive pattern with interstitial infiltrates and pleural effusion in both lung bases. Thorax angiotomography (Figs. 2 A,B) excluded pulmonary thromboembolism and showed increased heart volume associated with bilateral pleural effusion of moderate volume and ground-glass alveolar opacities. EKG findings included sinus tachycardia, first-grade atrioventricular block, and diffuse elevation of ST-segment with no reciprocal depression and low amplitude of QRS that were transitory. Echocardiogram showed enlargement of left cameras, with moderate to severe systolic dysfunction. Morphologic and functional studies by CMR disclosed a late gadolinium enhancement at ventricular septum and not in subendocardial region, compatible with myocarditis, and there was a moderate pericardial effusion (Fig 2 C, D). Moreover, focal hyperintense signals indicative of edema were observed on late gadolinium enhanced T2-weighted images. The following antibodies were reagent: ANA-HEp-2 (1/320) with dense fine speckled pattern; anti-SS-A/Ro (40 IU); anti-SSB/La (76 IU); and anti-ds DNA 1/80. Other determinations were unremarkable: P-ANCA, CANCA, anti-Jo-1, lupus anticoagulant, anticardiolipin, anti-Sm, and anti-RNP. The direct Coombs test was negative. Microbiologic pathogens were not detected either by urine or blood culture, or serologic tests. Thoracic changes improved (Fig 3) with treatment of congestive heart failure, antibiotics, and $1 \mathrm{mg} / \mathrm{kg} /$ day of prednisone. Pulse therapy with cyclophosphamide [800 mg $(0.5 \mathrm{~g} /$ $\left.\mathrm{m}^{2}\right)$ ], was administered soon after improvement of her general condition. Clinical evolution was uneventful and she was asymptomatic at discharge from hospital. Actually, she is using prednisone (2.5 mg daily), in good clinical condition under rheumatologic surveillance at outpatient service. 
Table 1. Routine laboratory data from a 72-old-female with late-onset SLE and myocarditis

\begin{tabular}{|c|c|c|c|}
\hline Parameters/ Days of admission & Day 1 & Day 6 & Day 8 \\
\hline Erythrocytes $\left(4.4-6.0 \times 10^{12} / \mathrm{mm}^{3}\right)$ & 3.12 & 2.50 & 2.99 \\
\hline Hemoglobin (11.1-16.1 g/dL) & 9,3 & 7,9 & 8,9 \\
\hline Hematocrit (39-53 \%) & 28,9 & 22,7 & 27,0 \\
\hline $\operatorname{MCV}(80-100 \mathrm{fL})$ & 93 & 91 & 90 \\
\hline Leukocytes $\left(4.0-11.0 \times 10^{3} / \mathrm{mm}^{3}\right)$ & 7.5 & 2.8 & 3.9 \\
\hline Leukocytes percent & $6,79,1,0,7,7$ & $3,77,0,0,15,5$ & $1,78,0,0,15,6$ \\
\hline Platelets $\left(150-450 \times 10^{3} / \mathrm{mm}^{3}\right)$ & 209 & 184 & 175 \\
\hline $\operatorname{ESR}(\leq 15 \mathrm{~mm} / \mathrm{h})$ & 47 & 28 & 38 \\
\hline C-reactive protein $(<0.100 \mathrm{mg} / \mathrm{dL})$ & 3.1 & 1.2 & 0.2 \\
\hline Urea $(10-50 \mathrm{mg} / \mathrm{dL})$ & 43.1 & 50.4 & 51.0 \\
\hline Creatinine $(0.7-1.3 \mathrm{mg} / \mathrm{dL})$ & 1.3 & 1.1 & 1.2 \\
\hline Sodium (135-145 mEq/L) & 128 & 124 & 132 \\
\hline Potassium (3.5-5.2 mEq/L) & 4.8 & 3.9 & 3.6 \\
\hline Calcium $(8.9-10.0 \mathrm{mg} / \mathrm{dL})$ & 8.7 & 6.9 & 8.6 \\
\hline Magnesium (1.6-2.6 mg/dL) & 2.1 & 2.0 & 2.1 \\
\hline Aspartate transaminase $(\leq 32 \mathrm{IU} / \mathrm{L})$ & 32.5 & 60.8 & 40.9 \\
\hline Alanine transaminase $(\leq 55 \mathrm{IU} / \mathrm{L})$ & 33.0 & 81.3 & 65.7 \\
\hline Alkaline phosphatase (40-150 IU/L) & 104.6 & 98.1 & $\mathrm{Nd}$ \\
\hline Albumin $(3.5-5.0 \mathrm{~g} / \mathrm{dL})$ & 3.8 & 3.5 & $\mathrm{Nd}$ \\
\hline Globulins (1.4-3.5 g/dL) & 2.9 & 2.4 & $\mathrm{Nd}$ \\
\hline Iron $(25-156 \mu \mathrm{g} / \mathrm{dL})$ & 54 & 72 & $\mathrm{Nd}$ \\
\hline
\end{tabular}

MCV: mean corpuscular volume; Leukocytes percent (normal ranges \%): bands ( $\leq 5)$, segmented (45-70), eosinophils $(\leq 7)$, basophils $(\leq 3)$, lymphocytes (20-50), monocytes (2-10); ESR: erythrosedimentation rate; Nd: not done. Abnormal data are showed in bold.

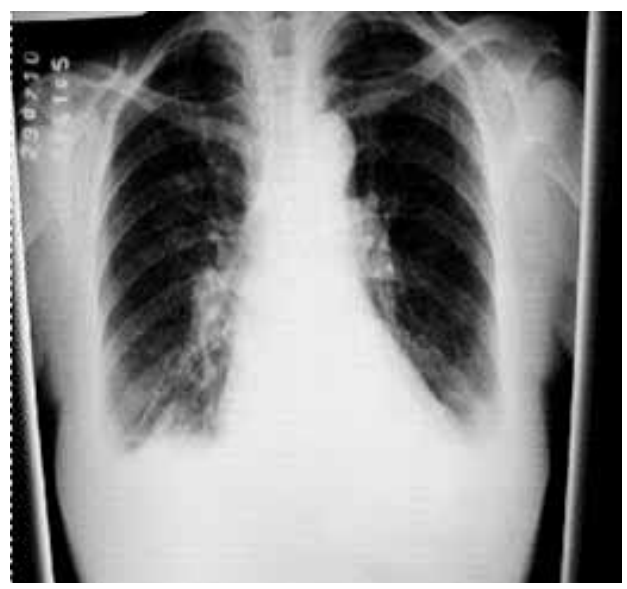

Figure 1. Chest X-ray at the hospital admission showing a congestive pattern.

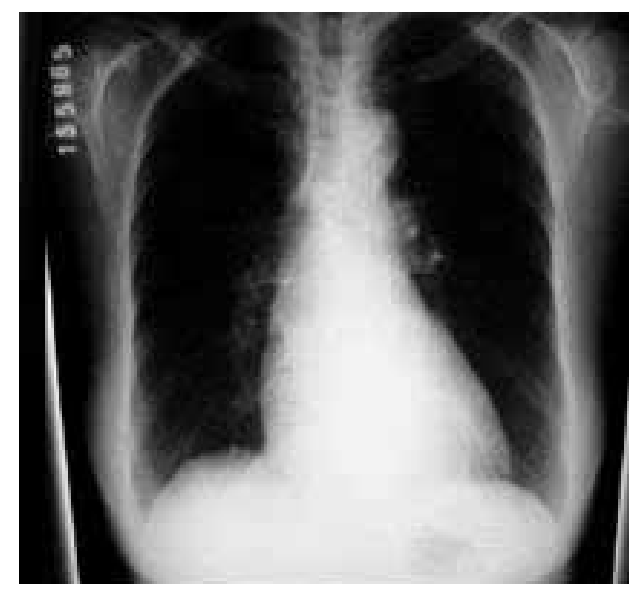

Figure 3. Chest X-ray of control after treatment, showing improvement of the initial changes. 


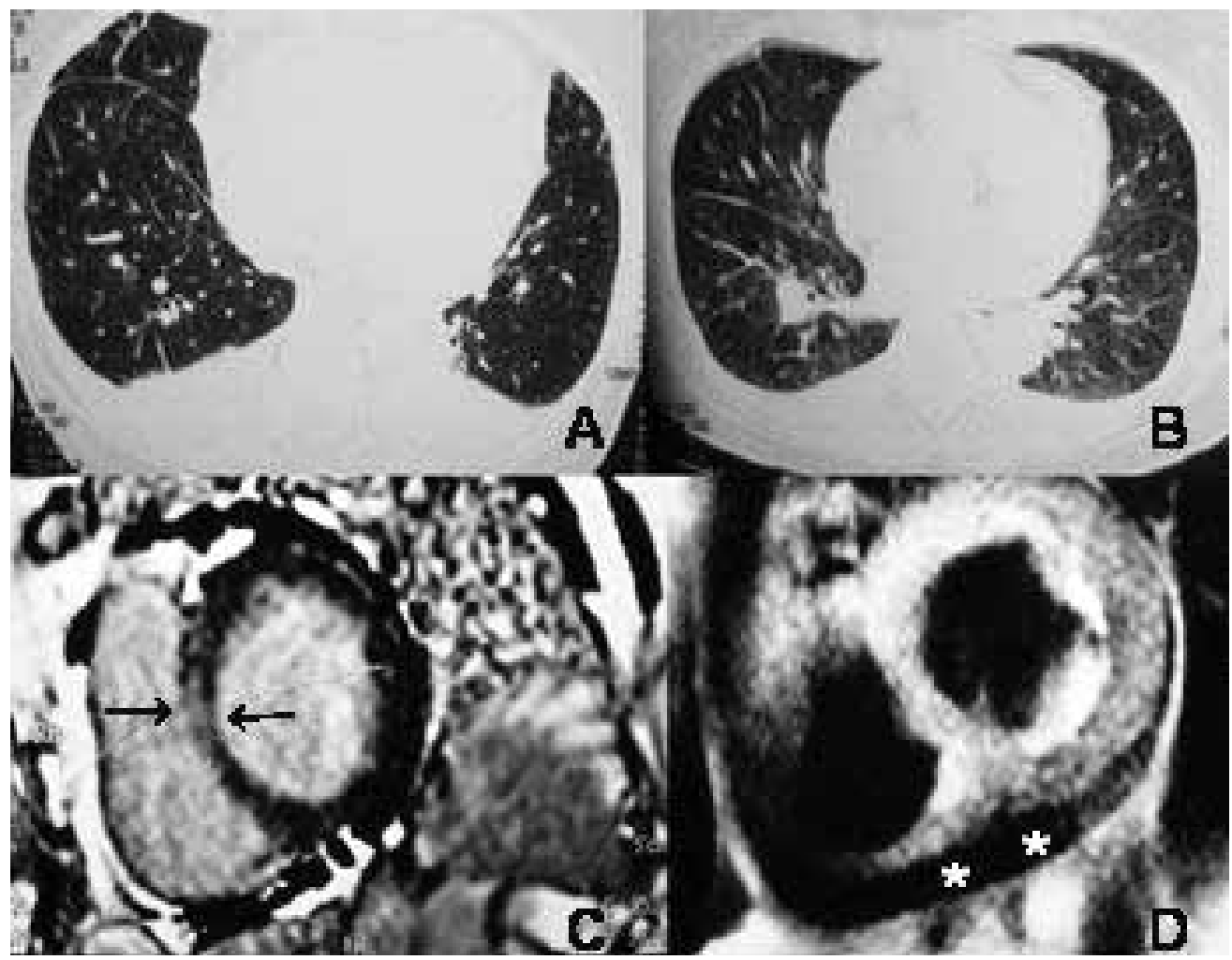

Figure 2 (A and B). Thorax CT evidencing increased heart volume associated with bilateral pleural effusion of moderate volume and ground-glass alveolar opacities; (C and D): Cardiac CMR disclosing image of late contrast enhancement at ventricular septum (arrows); and moderate pericardial effusion (asterisks).

\section{DISCUSSION}

Women with mean age of 53 years at diagnosis of SLE are under more than 2-fold increased risk of cardiovascular disease, and cardiovascular morbidity and mortality are higher in elderly people with SLE than in general population ${ }^{11}$. The diagnosis of SLE was established when the patient was 60-years-old. Arthritis and nephritis were not conspicuous, and cardiopulmonary features were predominant ${ }^{2-5}$. Anti-Ro and anti-La antibodies were positive, while anti-Sm and anti-RNP were negative, like described in patients with late onset SLE ${ }^{2-5}$. Recently, she had acute cardiopulmonary changes due to left heart failure. A major concern was about differential diagnosis with severe thoracic acute conditions like myocardial infarction, pulmonary thromboembolism and pneumonitis that are frequent among SLE patients and can cause heart failure. Clinical features and laboratory data, EKG, echocardiogram, and CMR contributed to rule out the alternative hypotheses $^{9}$.

Elderly patients with SLE often present with multiple simultaneous visceral involvement and/or secondary infections. These occurrences can hinder the diagnosis of coexistent heart changes, that may be observed in $30-50 \%$ of patients with SLE, and are mainly represented by pericarditis in $25-30 \%{ }^{10}$, while myocarditis is found in near $10 \%,{ }^{7,10}$. Moreover, endocarditis of Libman-Sachs and coronary disease are frequent complications of SLE ${ }^{6,10}$. Another concern was about the exact etiology of 
myocarditis. Microbiologic agents were not detected ${ }^{7}$, but the hypothesis of secondary cardiac infection was not entirely ruled out. Endomyocardial biopsy could have contributed to solve the diagnosis challenge ${ }^{6,10}$; however, more invasive procedures were avoided in this fragile patient.

The recent development of heart failure was concomitant with reduction in serum complement level and elevation of anti-ds DNA, strongly suggestive data of myocarditis by $\mathrm{SLE}^{10}$. Cardiac disturbances were successfully managed with supportive care, diuretic, angiotensin-converting enzyme inhibitor, and beta-blocker ${ }^{10,13}$. Despite of the good outcome in this patient with late onset SLE, this condition should not be considered of benign course $\mathrm{e}^{1,3,4,11}$. Moreover, the normal aging process may increase the mortality rate among old patients, as described in late onset SLE ${ }^{2,11}$.

Myocarditis is reported here in association with late onset SLE. Growing number of people over 65 years with lupus and other chronic disorders has increased the challenges of differential diagnosis. This condition must be cleared by proper investigation, because outcomes depend on prompt diagnosis and treatment. CMR is very useful to disclose and monitoring myocardial dysfunction and myocarditis ${ }^{8,9}$, and to guide endomyocardial biopsy (EMB) procedures, which could better characterize the origin of myocarditis. The main biopsy findings have been focal or diffuse plasma cell and lymphocyte interstitial infiltrates. Notwithstanding, as EMB is an invasive procedure with very low diagnostic yield ${ }^{13}$, the risk to benefit ratio was considered unfavorable in the particular case of this fragile old woman. The abrupt onset of chest pain and breathlessness was concomitant with a flare up of SLE. Additionally, pericardial effusion, inflammatory parameters and high CK-MB are suggestive of acute myocarditis. Although the data from EKG, echocardiogram and CMR studies were strongly indicative of an acute injury ${ }^{14-18}$, this condition could not be confirmed by EMB.

The final diagnosis of myocarditis is usually challenging and depends upon an early and high suspicion index. This clinical hypothesis should be confirmed following the criteria from respective diagnostic guidelines. $\mathrm{CMR}^{15-18}$ constitutes an excellent noninvasive method for diagnosing myocarditis, and any two of the following criteria should be fulfilled: regional or global increase in signal intensity on T2-weighted images; increased global myocardial early gadolinium enhancement ratio between myocardium and skeletal muscle in the T1-weighted images; and focal lesion with non-ischemic regional distribution in the late gadolinium enhanced images ${ }^{15,17}$. Limitations of this method include the lack of short-tau inversion recovery (STIR) imaging, that is considered the best approach for a more accurate evaluation of the abnormal presence of tissue fluid ${ }^{14}$; nevertheless, STIR has not been disposable for daily practice in most of the developing regions yet.

We also hypothesized subacute myocarditis and idiopathic dilated cardiomyopathy. Worthy of note, a typical subacute myocarditis has undetermined onset, and signs/symptoms as well as changes of complementary data are more persistent than observed in this patient ${ }^{18}$. An idiopathic dilated cardiomyopathy might be ruled out with basis on the description of Wozakowska-Kapton et al., who discussed features of acute and subacute myocarditis in 32 patients ${ }^{18}$. This woman had an evident active inflammatory process with myocardial injury, pericardial effusion, and confirmatory tests of an autoimmune disease as a potential cause ${ }^{18}$.

Interestingly, CK-MB was elevated while myoglobin and troponin had unremarkable levels. Troponin is a biomarker for the detection of myocarditis, but false positive/ negative results occur related to the troponin sensitivity (53\%), negative predictive value (56\%), specificity (94\%) and positive predictive value of $93 \%{ }^{19}$. The hypothesis of immunoassay interference seems strengthened in the present case, based on the usual concordance between results of CK-MB (non-immunoassay) and troponin in patients with myocarditis ${ }^{20}$.

In summary, this 72-year-old woman presented signs and symptoms sugges- 
tive of acute myocarditis coincident with a flare-up of late onset SLE, in the setting of laboratorial, EKG, echocardiography and CMR findings considered compatible with this diagnosis.

With limitations of a single case report, the purpose is to increase the suspicion index about the hypothesis of myocarditis associated with SLE, which should be investigated by clinical and laboratory evaluations, in addition to echocardiography and CMR studies.

\section{REFERENCES}

1. Appenzeller S, Pereira Da, Costallat Lt. Greater accrual damage in late-onset systemic lupus erythematosus: a long-term follow-up study. Lupus 2008; 17: 1023-1028.

2. Boddaert J, Huong Dl, Amoura Z, Wechsler B, Godeau P, Piette Jc. Late-onset systemic lupus erythematosus: a personal series of 47 patients and pooled analysis of 714 cases in the literature. Medicine 2004; 83: 348-359.

3. Lalani S, Pope J, De Leon F, Peschken C, Members of CaNIOS/1000 Faces of Lupus. Clinical features and prognosis of late-onset systemic lupus erythematosus: results from the 1000 faces of lupus study. J Rheumatol 2010; 37: 38-44.

4. Maddison P, Farewell V, Isenberg D, Aranow C, BAE Sc, BARR S, et al. The rate and pattern of organ damage in late onset systemic lupus erythematosus. J Rheumatol 2002; 29: 913917.

5. RovenskÝ J, Tuchynová A. Systemic lupus erythematosus in the elderly. Autoimmun Rev 2008; 7: 235-239.

6. Jain D, HalushKa Mk. Cardiac pathology of systemic lupus erythematosus. J Clin Pathol 2009; 62: 584-592.

7. Mavrogeni S, Spargias K, Markussis V, Kovolou G, Demerouti E, Papadopoulou E et al. Myocardial inflammation in autoimmune diseases: investigation by cardiovascular magnetic resonance and endomyocardial biopsy. Inflamm Allergy Drug Targets 2009; 8: 390-397.

8. WAssmuth R. Cardiac magnetic resonance imaging for myocarditis and nonischemic cardiomyopathies. Minerva Cardioangiol 2009; 57: 511-520.
9. Goitein O, Matetzky S, Beinart R, Di Segni E, Hod $\mathrm{H}$, Bentancur A et al. Acute myocarditis: noninvasive evaluation with cardiac CMR and transthoracic echocardiography. AJR 2009; 192: 254-258.

10. Costa S, Franco F, Monteiro P, Oliveira L, VieiRA H, GARRIDO L et al. Miocardite lúpica: a propósito de um caso clínico. Rev Port Cardiol 2005; 24: 1247-1257.

11. HaK Ae, Karlson Ew, Feskanich D, Stampfer Mu, Costenbader KH. Systemic lupus erythematosus and risk of cardiovascular disease. Results from the Nurses Health Study. Arthritis Rheum 2009; 15: 1396-1402.

12. Panchal L, Divate S, Vaideeswar P, Pandit Sp. Cardiovascular involvement in systemic lupus erythemathosus: an autopsy study of 27 patients in India. J Postgrad Med 2006; 52: 5-10.

13. Woo Si, Hwang Gs, Kang SJ, Park Js, Park SJ, LeE Ys et al. Lupus myocarditis presenting as acute congestive heart failure: a case report. J Korean Med Sci 2009; 24: 176-178.

14. Francone M, Carbone I, Agati L, Bucciarelli Ducci C, Mangia M, IACUCCI I et al. Utility of T2-weighted short-tau inversion recovery (STIR) sequences in cardiac MRI: an overview of clinical applications in ischaemic and nonischaemic heart disease. Radiol Med 2011; 116: 32-46.

15. Friedrich Mg, Sechtem U, Schulz-Menger J, Holmvang G, Alakija P, Cooper Lt, et al. Cardiovascular magnetic resonance in myocarditis: a JACC white paper. J Am Coll Cardiol 2009; 53 : 1475-1487.

16. JCS JOINT WORKING GROUP. Guidelines for diagnosis and treatment of myocarditis (JCS 2009) Digest version. Circ J 2011; 75: 734-743.

17. JiJI Rs, KRAmer CM. Cardiovascular magnetic resonance: applications in daily practice. Cardiol Rev 2011; 19: 246-254.

18. WozaKowsKa-Kaplon B, SzymczyK R, BaKowsKi D, Jaskulska-Niedziela E, BartKowiak R, StepienWALEK A et al. Myocarditis - clinical course and 2-year outcome in 32 patients. Kardiol Pol 2009; 67 :642-648.

19. Kelley We, Januzzi Jl, Christenson Rh. Increases of cardiac troponin in conditions other than acute coronary syndrome and heart failure. Clin Chem 2009; 55: 2098-2012.

20. Ismail Y, Ismail Aa, Ismail AaA. Erronmeous laboratory results: what clinicians need to know. Clin Med 2007; 7: 357-361. 